die Doppelseitigkeit der Augenaffection spricht dagegen. Und der Befund innerbalb der Schädelhöhle lässt nichts erkennen, was auf ein Fortkriechen in solcher Weise hindentete. Vielmehr ist die Affection rechts wie links von derselben Besehaffenbeit und voraussichtlich von etwa demselben Alter.

Wie häufig eine derartige Entwickelung der Meningitis acuta vorkommt, darüber lässt sich vor der Hand nichts Sicheres sagen. Möglich, dass ich nur zufällig Gelegenheit hatte, sie innerhalb eines Jahres dreimal zn sehen. Es ist aber nicht unwahrscheinlich, dass ejn Theil der Fälle hierherzuzählen ist, wo sich anscheinend in Folge eines Gesichtserisypels durch Vermittelung einer eitrigen Infiltration des orbitalen Zeligewebes acute Meningitis entwickelt zu haben schien. Das Oedem mit der venösen Röthung kann leicht für Erisypel gehalten und die Meningitis, welche erst später erkannt wird, als Folge angesehen werden.

4.

\title{
Fall von Paralysis agitans des rechten Armes in Folge der Entwickelung eines Sarkoms im linken Thalamus.
}

\author{
Von E. Leyden.
}

Bei den geringen Kenntnissen, welche wir von den Ursachen der sogenannten Paralysis agitans baben, dürfte der folgende Fall von Interesse sein, welchen Herr Stabsarat Teuber bei einem Soldaten zu beobachten Gelegenheit hatte.

St., 24 Jabre alt, dient seit 2 Jahren und 7 Monaten, ist Gefreiter, rept. am 21. Mai 1863. Er war früher immer gesund gewesen und will namentlich an Syphilis nie gelitten haben, ebensowenig vermag er einen Fall, Stoss oder sonstige Verletzung als Ursache seiner jetzigen Krankheit anzuklagen, auch einer nachweisbaren Erkältung bat er sich nicht ausgesetzt. An Kopfschmerzen, behauptete er bei seiner Aufnahme, nicht gelitten zu haben; einige Tage später aber gab er an, dass er seit etwa 8 Tagen öfters einen klopfenden Schmerz in der Stirngegend empfunden habe. Die ersten Symptome motorischer Störung im rechten Arm hat Patient seit Anfang April d. J. bemerkt; sie bestanden darin, dass der Arm leicht zitterte, zumal bei etwas grösseren Anstrengungen, doch konnten die unwillkürlichen Bewegungen nocb vollständig beherrscht werden, so dass der Gebrauch der Hand nicht behindert war. Namentlich batte die Kraft des Armes in keiner Weise gelitten. Mit der Zeit aber nabm die Intensität der unwillkürlichen Zuekungen inrner mebr zil, so dass sie hinderlich wurden, und der Kranke das Lazareth aufsuchen musste.

St. praes. Pat. ist gut und kräftig gebant, gut genäbrt, von guter Färbung der Wangen und Lippen. Er klagt über unwillkürliche zitternde Bewegungen des rechten Armes, die er zwar auf kurze Zeit beherrschen kann, die aber dann wieder sogleich mit grösserer Intensität auftreten. Dabei sind die einzelnen willkürlichen 
Bewegungen des Armes und der Hand nicht behindert, auch hat die Kraft derselben nicht wesentlich gelitten: wenigstens ist der Druck der Hand ebenso kräftig als linkerseits. Im Schlafe cessiren die unwillkürlichen Bewegungen. Dieselben besteben in äusserst schnell abwechselnden, kurzen Pro- und Supinationsdrẹungen des Vorderarmes um seine Längsachse; sie erfolgen etwa 200 Mal in der Minute. In beinem Gelenke des Armes oder der Hand besteht eine Contractur. Die Muskulatur ist kräftig, keineswegs abgemagert. Die Sensibilität lässt in keiner Weise Abweichungen erkennen.

Das ïbrige Befinden ist angeblich ungetrübt. Pat. hat über Nichts weiter zu klagen. Fieber ist nicht vorhanden. Das Sensorium ist anscheinend frei. Pat. antwortet auf die ihm vorgelegten Fragen angemessen, docb etwas langsam, der Gesichtsausdruck ist etwas stupide, die Sprache erscheint zuweilen etwas schwerfällig.

Am 24. Mai Morgens tritt Erbrechen ohne Uebelkeit ein: dasselbe wiederholt sich Abends. Pat. klagt über Kopfschmerz. Puls 64. Temperatur kaum erhöht.

Den 25. Mai. Temperatur $39^{\circ}$, Puls 60.

Den 26. Mai. Klage über klopfenden Schmerz in der ganzen Stirngegend.

Am 6. Juni wurde zuerst eine Erweiterung der linken Pupille beobachtet, und zwar erschien dieselbe zugleich schräg verzogen: auf Atropin erfolgte leicht vollständige und gleichmässige Dilatation. - Die zitternden Bewegungen des rechten Armes bestehen unverändert fort; das übrige Befinden ist gut, jedoch bat der schon früher bemerkbare Stupor zugenommen, das Gedächtniss hat entschieden gelitten. Von Zeit zu Zeit klagt Pat. über Kopfschmerzen und Schwindel.

Am 12. Juli verfiel Pat. plötzlich in einen comatösen Zustand, in dem er auf keine Fragen antwortete, vollkommen besinnungslos war und Urin wie Fäces unter sich liess. Nachts erfolgte mehrmals Erbrechen. Indessen liess die Intensität dieser Symptome allmälig wieder nach, und 6 Tage später ist Patient wieder besinnlich, antwortet, wenn auch langsam und schwerfällig auf die ihm vorgelegten Fragen. Lähmungserscheinungen sind nicht eingetreten, die Zitterbewegungen des rechten Armes bestehen unverändert fort.

In der ersten Hälfte des Monat August hatte sich der Stupor noch vermehrt, der Krarke schlief viel, war, auch erweckt, schwer besinnlich, die Sprache war langsam, stotternd, der Urin ging fast immer unwillkürlich ab, offers anch der Stuhlgang. Die Bewegungen der Extremitäten waren langsam, die Reaction auf sensible Reize erfolgte spät und unvollkommen. Rechterseits erschienen die Bewegungen des Armes noch langsamer und energieloser als links, doch ist von einer eigentlichen Paralyse kejne Rede. Die zitternden Bewegungen des Armes dauern fort; sie treten ein, sowie der rechte Arm erhohen wird.

Im Monat September entwickelte sich ein vollsommen comatöser Zustand. Pat. scheint völlig ohne Bewusstsein und antwortet nicht mehr selbst auf ejnfache Fragen. Er muss gefüttert werden. Urin und Fäces lässt er unter sich. Bewegungen erfolgen auf selbst starke Hautreize langsam, aber sie erfolgen in allen Extremitäten und im Gesicht, im rechten Arme fast ebensognt wie im linken. Dagegen hat sich eine Contractur in rechten ElJbogengelenk ausgebildet, welche auch mit Gewalt nicht zu überwinden ist. Sowie man den. Versuch macht, den Arm 
zo strecken, gerätlı er in die früheren kurzen klonischen Zuckungen. Aucb der linke Arm zeigt jetzt zuweilen ähnliche zitternde Bewegungen. Die Augen stieren ohne Fixation umber. Pat. ist durch Nichts mehr aus seinem Coma zu erwecken, daher auch nicht zu constatiren ist, ob er hört oder sieht. - Beginnender Decubitus. Abmagerung.

Die ophthalmoskopische Untersuchung der Augen ergibt: trübe Beschaffenheit der ganzen Retina, die Gefässe verdeckt, nur die grösseren venösen Stämme sind zu erkennen. Die Opticusscheibe hat ein gequollenes, trübes Ausseben, die centralen Gefässe sind verschwunden, nur grosse, dicke Venen zu erkennen, auch diese nicht bis zur Peripherie der Opticusscheibe zu verfolgen. Die Venen der Retina sind stark erweitert und geschlängelt. Neben dem 0 pticus liegen links mehrere kleine, rechts ein grosses (frisches) Blutextravasat. Das ophthalmoskopische Bild ist dadurch getribt, dass die Cornea nicht ganz klar ist, sie ist durch kleine, epitheliale Substanzverluste facettirt. Die Conjunctiva ist injicirt, besonders rechts. Beide Pupillen eng, erweitern sich jedoch leicht durch Atropin.

Am 14. October ein apoplectiformer Anfall, in Folge dessen Lähmung der linken Gesichtshälfte eintritt (Aufblähen der Backe durch den exspiratorischen Luftstrom).

Tod am 18. 0ctober.

\section{Obduction.}

Der Schädel ist gross, ziemlich breit: in der Gegend der Pfeilnaht findet sich nach links von der Mittellinie eine äber erbsengrosse Stelle, wo der linochen vollständig perforirt, nur von der Sella bedeckt ist: die Innenfläche zeigt entsprechend der Kranznaht eine tiefe Furche, welche an der beschriebenen Stelle bis zur Perforation vorgeschritten ist. Hinter dieser Furche ist die innere Schädelfäche dunkel geröthet und die Lamina vitrea bis auf kleine Reste vollständig atrophirt, welche Reste wie kleine Sandkörner äber die Innenflăche zerstreut sind: an der Sägefläche ist die Atrophie der inneren Lamelle deutlich zu erkennen, auf solche Weise ist die poröse blutreiche Schicht der Diploë an die innere Oberfläche getreten. Auch das Stirnbein zeigt eine ähnliche, jedoch weniger weit vorgeschrittene Atrophie der inneren Glasplatte, so dass dieselbe eine sebr unebene, höclirige Oberfläcbe darbietet. - Das Gehirn quillt aus der Schädelbasis stark hervor, die Dura ist prall, gespanut, links etwas stärker prominirend als rechts. Vorn entsprechend der Kraoznabt finden sich neben der Mittellinie frei unebene, warzige flache Prominenzen, von denen die linke der beschriebenen Perforation des Schädels entspricht. Die nura ist hier ziemlich fest mit der Pia durch. Adbäsionen verlöthet. Die Gyri sind stark abgeflacht. Die Venen der Pia bis in die kleinsten Stämmchen hinein beträchtlich erweitert und von Blut strotzend. Die Pia selbst ist etwas ödematös. Von der Basis fliesst beim Anschneiden des Tentorinm eine erhebliche Menge klarer, seröser Flüssigkeit aus. Aucb an der Basis zeigt die Pia starke Füllung der venösen Gefässe, aucb hier sind die Gyri stark abgeflacht, ebenso der Pons und die Nervi optici.

Beide Ventrikel sind stark erweitert und mit klarer Flïssigkeit gefïllt, auch der linke Ventrikel ist weit. Der Thalamus opticus der linken Seite prominirt be- 
dentend stärker als der rechte und bildet eine fast apfelgrosse, randliche Geschwulst, durch welche die Vena magna bogenförmig nach rechts verschoben ist. Die Consistenz dieser Geschwulst ist an der. Oberfläche, wo sie ein gelblich geflecktes Aussehen bal, geringer als die normaler Hirusubstanz. Auf dem Durchsclnitt zeigt sich die Substanz des Thalamus durch eine runde, über wallnussgrosse Geschwulst auseinander gedrängt, weiche nach oben zu bis an die oberläclue reicht, nicht mehr von Nervensubstanz bedeckt. Sie zeigt im Innern ein sehr buntes Ausselıen. Das Centrum ist durch eine geibe, mürbe, fast käsige Masse gebildet, äber derselben liegt eine Schicht von rothen, markigen Gewebe von derber Coum sistenz, die oberflächliche Schicht hat ein fast cavernöses, grobzelliges Aussehen, Indem in ein Gerüst von der Beschaffenheit der zweiten Schicht theilweise gelb liche Heerde eingestreut, theils durcb Ausfallen solcher zellige Räume entstanden sind. In Ganzen hat die Masse eine elastisch derbe Consistenz, bei Druck entleert sich kein Krebssaft.

Die übrige Substanz des grossen, wie des kleinen Gehirns zeigt bis auf grosse Blässe neben Erweiterung der venösen Gefässe nichts Besonderes. Nirgends findet sich eine zweite Geschwulst.

In beiden Augen zeigt sich die Opticusscheibe gequollen, leicht gelblichweiss, trübe, die Gefässe verdeckt, nur in der Mitte zu erkennen; neben dem Rande der Opticusscheibe befinden sich beiderseits auf der der, Macula lutea (welche übrigens sebr gut erhalten ist) entgegengesetzten Seite frische streifige Blutextravasate, links mebrere kleinere, rechts ein grosses confluirendes.

Bei der mikroskopischen Untersuchung erwies sich die Geschwulst als ein Sarkom, bestehend aus meist langen spindelförmigen ein- his mehrkernigen Zellen, zwischen denen zahireiche Fettkörnchenconglomerate zerstrent lagen. - In der Retina fanden sich ebenfalls sehr zah/reiche Fettkörnchenconglomerate in mehreren zerstreuten Heerden, welche zum grössten Theil in der Nähe der Blutextravasate lagen, jedoch theilweise auch in grösserer Entfernung davon. Sklerotische (gequollene) Nervenfasern konnten nicht gefunden werden.

5.

Notiz über eine ungewöhnliche Missbildung.

Von Prof. Möller in Königsberg.

(Hierzu Taf. VII. Fig. 2.)

Das rechtzeitig geborene, aber dürftig genährte Kind der Frau K., welche während ihrer Schwangersehaft schweren und anbaltenden Kummer gehabt, hatte nur schwach geschrieen, die Brust nie recht genommen, gewöhnliches Meconium in beträchtlicher Menge, aber nur sehr wenig_trüben Harn entleert. Es war hereits am 3ten Tage nach der Geburt unter zunehmender Lebensschwäche gestorben. 